\title{
The Institute for Computational and Experimental Research in Mathematics (ICERM)
}

\section{Jill Pipher, Sergei Tabachnikov, and Homer F. Walker}

The Institute for Computational and Experimental Research in Mathematics (ICERM) is a National Science Foundation Mathematical Sciences Re-

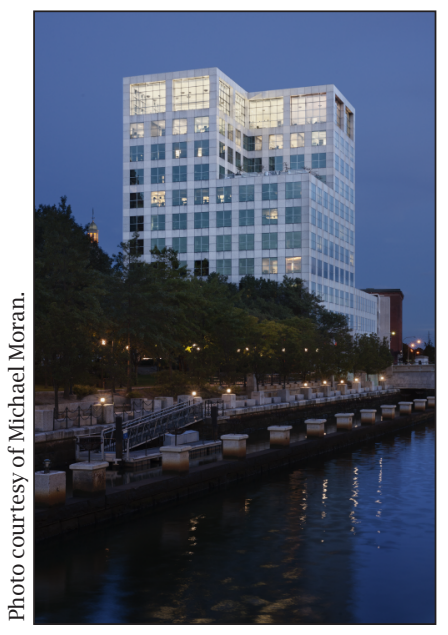

ICERM occupies the top two floors of a Brownowned building in downtown Providence. search Institute at Brown University. Minutes from the main Brown campus, it occupies the top two floors of a Brown-owned building in downtown Providence, overlooking the Providence riverfront. Open since 2011 , thousands of visitors have come to ICERM in its first four years of operation and well over a thousand are expected in the coming year. Activities range from faculty and student research programs to a week-long day camp for high-school girls (see upcoming programs and events at icerm. brown . edu, )

Jill Pipher is the Elisha Benjamin Andrews Professor of Mathematics at Brown University and Director of ICERM. Her email address is jpi pher@math. brown. edu.

Sergei Tabachnikov is a professor of mathematics at Pennsylvania State University, former Deputy Director of ICERM, and current Chair of ICERM's Education Advisory Board. His email address is tabachni@math. psu. edu.

Homer F. Walker is a professor of mathematics in the mathematical sciences department at Worcester Polytechnic Institute, and Deputy Directory of ICERM. His email address is walker@wpi . edu.

For permission to reprint this article, please contact: reprint-permission@ams.org.

DOI: http://dx.doi.org/10.1090/noti1348
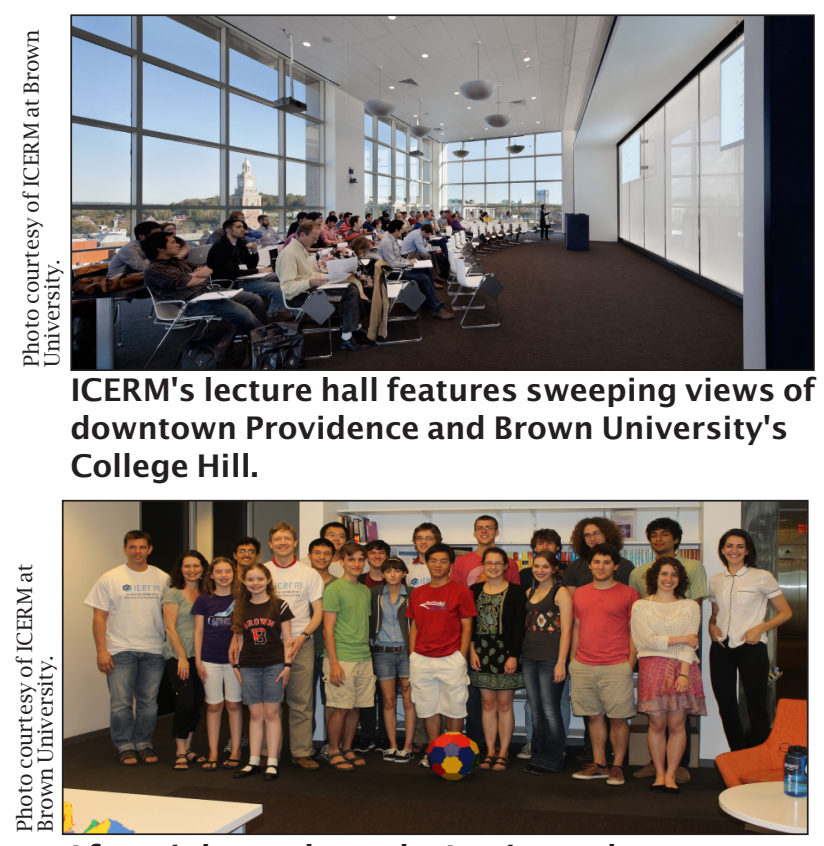

After eight weeks at the Institute, the Summer@ICERM2014 undergraduate students, organizers and TAs pose together on their last day of the program.

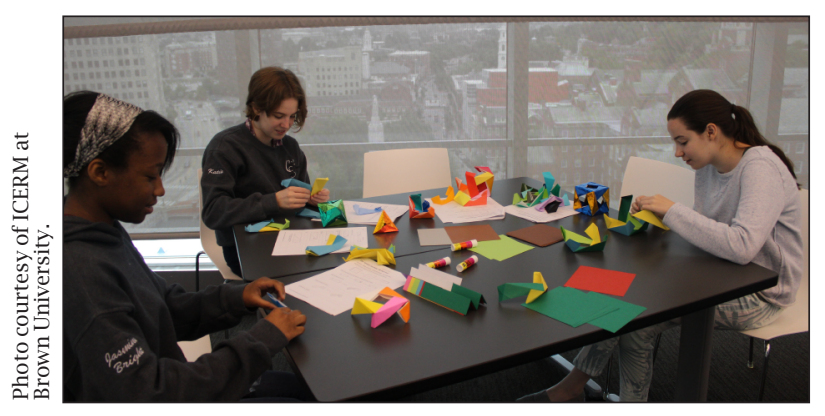

GirlsGetMath@ICERM participants explore mathematical sciences through hands-on activities, computations, and experimentations. 
The Public Face of ICERM

ICERM invites the community to its popular
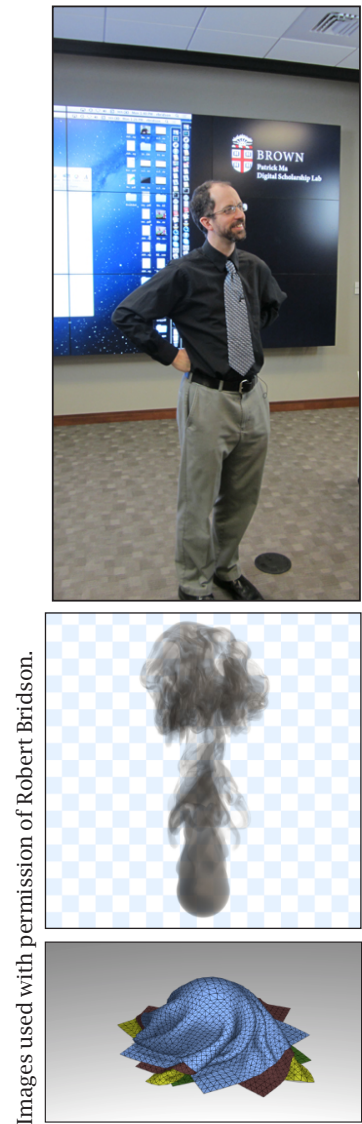

Robert Bridson and a still from his public lecture on computational physics.

public lecture series, which introduces nonspecialists to the wide range of mathematical topics that feature experimentation, computation, and visualization. Some of these lecture speakers also contribute video "shorts" to ICERM's MathBytes@ ICERM series.

Here are some highlights from the Public Lecture series.

Public Lecture: "Scratching the Surface in Dynamic Visual Effects" (March 11, 2013) https: //icerm. brown . edu/ssvde/.

Want water waves synchronized with music in movies? Robert Bridson (University of British Columbia) showed how computational physics underlies some of the most amazing and the most routine visual effects in films. His geometric and numerical algorithms in physics-based animation produce natural-looking water, smoke, fire, and clothing to create previously unrealizable artistic effects.

Public Lecture: "Mathematics of Crime" (November 20, 2014) https://icerm.brown.edu/ public_lectures/p1-14-moc/.

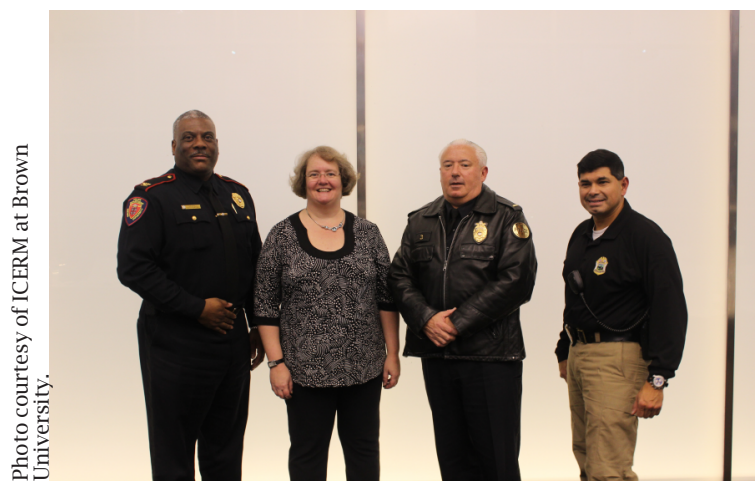

Andrea Bertozzi (second from left) stands with (L-R) Colonel Mark J. Porter and Lt. Kevin O'Connor (Brown University Police), and Lt. Luis San Lucas (Providence Police).
Using mathematical models to fight crime? Andrea Bertozzi (UCLA and Founding Chair of ICERM's Science Advisory Board) told the fascinating story behind her participation on the UCLA team that developed a "predictive policing" computer program that zeros in on areas that have the highest probability of crime. City of Providence and Brown University police were among the appreciative attendees.

Public Lecture: "Mathematics of Cooking" (March $17,2015)$ https:// icerm. brown. edu/pub7ic_1ectures/p1-15cook/.

How are eggs like snow? Dr. Michael Brenner (Harvard University) and Mark Ladner (Executive Chef, Del Posto Restaurant in New York City) teamed up to explain packing, phase transitions, elasticity and
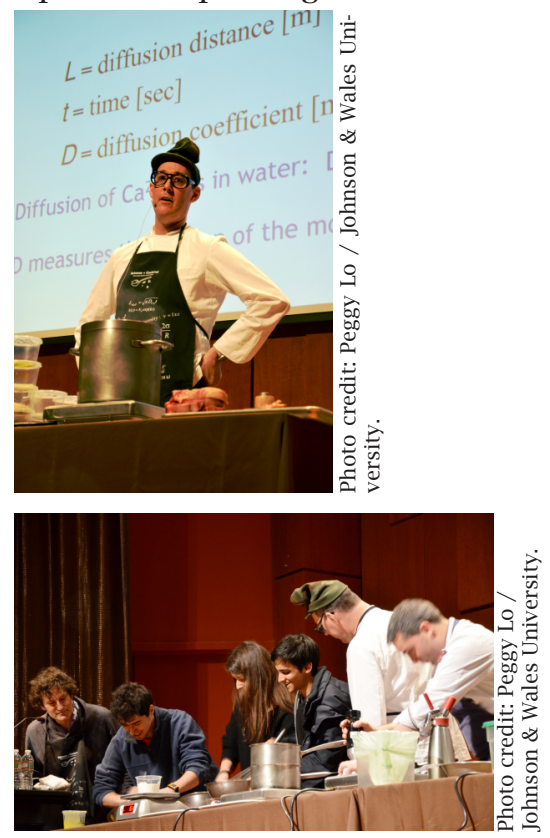

diffusion to a packed audience at Brown's Salomon Center. They experimented with eggs, wheat gluten, marshmallows, lime juice, $M \& M^{\prime}{ }^{\circledR}$, and green marshmallow Peeps ${ }_{\circledast}$, using hot pans, blowtorches, and liquid nitrogen.

\section{Looking Ahead}

ICERM is expanding its computing offerings to participants. In addition to providing access to multiple software packages and to high-performance computing through Brown's Center for Computing and Visualization, ICERM staff will also be available for programming consulting. ICERM is launching a new program in 2015, Collaborate@ ICERM, and encourages proposals for small teams of researchers who may benefit from ICERM's computing resources (see https://icerm. brown. edu/get_involved/\#tab-col1ab/.)

Finally, in July 2016, ICERM will welcome its second director, Brendan Hassett, a professor in the Mathematics Department at Brown University. 